'llu. Revista de Ciencias de las Religiones

ISSN: $1135-4712$

http://dx.doi.org/10.5209/ILUR.61025

\title{
La tesis de Weber en torno al capitalismo en el 500 Aniversario de la Reforma Protestante
}

\author{
Ignacio Carlos Maestro Cano ${ }^{1}$
}

Resumen. La tesis de Weber respecto a una hipotética huella del protestantismo en el «espíritu» del capitalismo ha sido ampliamente difundida. Sin desmerecer su planteamiento (la indemostrabilidad no resta verosimilitud), lo cierto es que, siendo una hipótesis difícilmente falsable, de ella han derivado formulaciones poco cuidadosas que vendrían a justificar las actuales circunstancias económicas con hechos religiosos diferenciales. Siendo la religión un hecho omniabarcador sin igual, tales circunstancias dependen de muchos factores. Se ha pretendido conferirle validez científica a partir de datos socioeconómicos de lo más variado. Algo aplicable también a quienes pretenden refutarle. La intoxicación dimanada así del trabajo de Weber resulta desconcertante, viéndose en él desde un intento de legitimar al capitalismo, hasta una confirmación de la Leyenda Negra. Este trabajo no pretende apoyar o refutar la tesis, sino revisar qué cuestiones pudieron dar pie a su formulación. Para ello, se incide sobre cuestiones poco habituales, como es el análisis de aquellos rasgos doctrinales del protestantismo (fundamentalmente la sola fe y la predestinación) de los que habrían derivado los argumentos de Weber.

Palabras clave: Protestantismo; capitalismo; Weber.

\section{[en] The Weber Thesis on Capitalism in the $500^{\text {th }}$ Anniversary of the Protestant Reformation}

\begin{abstract}
The Weber thesis on a hypothetical imprint of Protestantism in the «spirit» of capitalism has been widely spread. Not willing to discredit his proposal (indemonstrability does not detract from plausibility), the truth is that, being falsifiable with difficulty, some careless wordings have been derived from it claiming to explain the present economical circumstances through differential religious facts. Being religion an unparalleled all covering feature, such circumstances depend on many factors. It has been claimed some scientific status through the most diverse socioeconomic data. This is something also applicable to those who claim to refute him. The intoxication so emanated from the Weber's work seems disconcerting, seeing in it from an attempt to legitimate capitalism to a confirmation of the Black Legend. This work does not try to support or reject the thesis, but to investigate the kind of issues that could cause its formulation. For this purpose, it focuses on less usual questions, such as the analysis of the doctrinal features of Protestantism (basically faith alone and predestination) from which the Weber's arguments would arise.
\end{abstract}

Keywords: Protestantism; Capitalism; Weber.

Sumario. 1. Introducción. 2. Capitalismo o mammonismo. Emprendimiento o codicia. 3. El cuestionamiento de las obras como fundamento de la ética protestante. 4. La tesis de Weber a la luz del encuadre propuesto. 5. Síntesis conclusiva. 6. Bibliografía. 6.1. Fuentes. 6.2. Elenco bibliográfico. 6.3. Referencias hemerográficas.

1 Universidad de Valencia (España).

Correo electrónico: igmaeca@gmx.ch 
Cómo citar: Maestro Cano, I. C. (2018), La tesis de Weber en torno al capitalismo en el 500 Aniversario de la Reforma Protestante, en 'Ilu. Revista de Ciencias de las Religiones 23, 149-173.

\section{Introducción}

El estudio sobre el modo en que la racionalidad se presenta en la organización del mundo o influye sobre ésta es una constante en los trabajos de Weber como uno de los fundadores del estudio moderno de la sociología. Esto es algo que se aprecia de manera especial -y ha tenido una influencia muy destacada- en el caso de su obra $L a$ ética protestante y el «espíritu» del capitalismo. En tal obra se advierte el interés específico por la forma en que la ética ha podido intervenir en la organización, en este caso económica, del mundo. En este sentido, tanto en la obra de Weber como en la de quienes en su misma línea desarrollaron posteriormente este estudio, la ética es entendida como la forma en que se presenta la racionalidad humana a la hora de establecer aquello que ha de considerarse virtuoso o execrable (sea adhiriéndose a determinada doctrina religiosa o no). En cualquier caso y dada la importancia y manifiesta transversalidad del fenómeno religioso en las sociedades humanas, resulta comprensible el interés surgido por esta cuestión y que se estableciera, o al menos se explorase, alguna clase de conexión entre las esferas económica y moral.

Como es sabido y será desarrollado aquí, la polémica en torno a la tesis de Weber, relativa a una conexión más o menos directa entre la ética propia del protestantismo y los fundamentos del capitalismo, viene debatiéndose de manera ininterrumpida aun cuando lo cierto es que en rara ocasión surgen aportaciones realmente novedosas o clarificadoras. En cualquier caso, la cuestión permanece, un siglo después, abierta, habiendo dado lugar su análisis a múltiples y destacadas aportaciones como es la recogida en España por Rodríguez ${ }^{2}$. Parece estarse, tal y como se ha dicho, ante una de las controversias «más prolíficas de toda la historia de las ciencias sociales» ${ }^{3}$. Así, cuando ya parece que esta prolongada «guerra académica»-como la ha caracterizado Gil Villegas ${ }^{4}$ - constituye un debate agotado y al que difícilmente es posible añadir algo nuevo, son publicados nuevos datos que tratan de respaldar o refutar la tesis fundamental de Weber o simplemente sucede que algún acontecimiento, de un modo más o menos natural, vuelve a poner de actualidad la cuestión. Ello a pesar de que, tal y como también se ha dicho, «la tesis weberiana ha sido (...) tradicionalmente materia de malos entendidos y malas interpretaciones, especialmente cuando se la considera una hipótesis susceptible de ser empíricamente verificada o refutada en la actualidad $»^{5}$. Es por ello que este trabajo pretende centrarse más en profundizar sobre la vertiente cultural subyacente antes que sobre la polémica más usual: la de la validez o no de la tesis en la formulación propuesta por Weber. En este sentido, se trata aquí de desarrollar y documentar aquellos rasgos a los que Weber hizo mención de un modo más genérico y que es posible apreciar en las diferentes doctrinas surgidas a partir de la reforma de Lutero. Por otra parte, de entre las distintas dimensiones apreciables en torno a esta controversia (económica, sociológica, política, teológica, etc.), este trabajo pretende centrarse en la que se aproxime más a sus fundamentos y

\footnotetext{
Rodríguez 2005.

Boltanski y Chiapello 2011, $750 \mathrm{n}$.

Gil Villegas 2003, 9.

Gil Villegas 2005, 159.
} 
que podría por ello denominarse más «espiritual», si bien en un sentido más hegeliano que religioso del término. Aquella que se centra en la clase de creencias e íntimas convicciones que, operando en cada individuo, pudieron desembocar en esa tesis de Weber que a menudo ha sido interpretada en términos de «el protestantismo dio origen a...». No se tratará aquí de si capitalismo y protestantismo quedaron legítimamente emparentados por Weber, sino de a qué tipo de cuestiones hacía referencia Weber cuando propuso dicho parentesco. No ha de olvidarse que Weber habló en términos de «afinidades electivas» (Wahlverwandtschaften), lo que, si nos atenemos al sentido original del término en la conocida novela de Goethe ${ }^{6}$, podría traducirse al castellano como mera «compatibilidad de caracteres»; en este caso, entre protestantismo y capitalismo. Siendo así, ha de comenzarse recordando que la mera compatibilidad de caracteres no implica parentesco. Es razonable admitir que protestantismo y capitalismo no son incompatibles, pero de ahí a situar en el protestantismo el origen del capitalismo, hay un largo -y quizás demasiado retorcido- recorrido. Tal y como se ha expresado, "tanto "el espíritu del capitalismo" como "la ética protestante" están construidos por Weber como tipos ideales, y (...) la relación entre ellos no está planteada en términos de una causalidad directa, simple y mecánica, sino en términos de una afinidad que apela más al parentesco de una estructura significativa que a una relación causa-efecto» ${ }^{7}$. No obstante, para algunos autores, lo que Weber sostiene es que «la ética protestante fue una condición necesaria y que, sin ella, el desarrollo [del capitalismo] habría sido radicalmente diferente ${ }^{8}$. Una afirmación que, por otra parte, no parece aportar demasiado si se piensa en lo que expresara Meehl acerca de que, en realidad, «siendo la estructura causal y compositiva del pensamiento y la sociedad (...) la que es, casi todas las variables que medimos están correlacionadas en alguna medida»" ${ }^{9}$; «en las ciencias sociales todo se correlaciona con casi todo lo demás ${ }^{10}$. En este sentido, la influencia del protestantismo podría compararse a la de cualquier otra variable que pudiera admitirse como mínimamente plausible.

Por otro lado, incluso si se optara por hablar en términos no ya de compatibilidad sino de causalidad, no debiera pasarse por alto que la misma noción de causalidad ha sido y continua siendo una cuestión no exenta de problemática. Esto es así desde Hume y su comprensión de la causalidad como simple hábito o costumbre hasta nuestros días. Así, la confusión entre los conceptos de secuencialidad (la Reforma se produjo y después vino el capitalismo) y causalidad (la Reforma se produjo y, como consecuencia de ésta, vino el capitalismo) es algo que, como se verá, es posible encontrar incluso en medios científicos reconocidos. Ya Venn ${ }^{11}$ subrayó la distinción entre causalidad y regularidad, un concepto que posee una clara conexión con el incremento de la cantidad de datos disponibles en la actualidad acerca de cualquier fenómeno. Hoy en día, la difusión (casi popularización) de determinadas técnicas estadísticas, como pueda ser el análisis de regresión, permite contraponer con facilidad toda clase de fenómenos, forzándose a veces la identificación de conexiones o relaciones causales que, más allá de los números obtenidos (coeficientes de determi-

\footnotetext{
Goethe 1809.

Gil Villegas 2005, 162.

Parsons 1948, 294.

Meehl 1997, 393.

Meehl 1997, 402.

Venn 1866, 336.
} 
nación, etc.), resultan difíciles de admitir. Una situación que podría enmarcarse en el contexto de aquella denuncia de Horkheimer (1947) acerca de que «el pragmatismo justificó desde sus comienzos implícitamente la difundida sustitución de la lógica de la verdad por la de la probabilidad, que desde entonces es la que ha venido, con gran diferencia, a convertirse en la predominante $\rangle^{12}$, de manera que «la probabilidad, $\mathrm{o}$, mejor aún, la calculabilidad sustituye a la verdad $\rangle^{13}$.

Ciertamente, y entrando ya en la cuestión de las implicaciones que la religión haya podido tener sobre nuestra forma de actuar en la vida cotidiana, decía Alexis Tocqueville que:

apenas existe acción humana, independientemente de lo particular que sea el carácter que se le atribuya, que no se origine en alguna idea muy general del modo en que los hombres han concebido la Divinidad, Su relación con la humanidad, la naturaleza de sus propias almas y de sus deberes hacia sus semejantes. Como tampoco nada puede impedir que estas ideas constituyan la fuente común de la cual emana todo lo demás ${ }^{14}$.

Es por ello que no cabe duda de que Weber tiene razón cuando se ampara en el hecho de que «en un época en la que el más allá lo era todo (...) son los poderes religiosos (...) en la práctica los verdaderos escultores del "carácter de un pueblo" $\gg$ ", debiendo admitirse que resulta verosímil reconocer cierta impronta religiosa en la vida económica de nuestras sociedades. Al fin y al cabo, si entendemos la vertiente más práctica de la religión como una búsqueda de la virtud (cambiando de una a otra confesión lo que por tal se entienda), se trataría de averiguar si las virtudes «protestantes» favorecieron o eran portadoras, por así decir, del germen del progreso económico; al menos en mayor grado al modo en que pudiera haberlo hecho el catolicismo, por ceñirnos al ámbito occidental.

Dicho esto, lo primero que podría criticársele a Weber es que hablara en el título de su obra de «la» ética protestante ya que no debe olvidarse que ese complejo conglomerado de creencias que, por simplificar, se viene denominando protestantismo habría de dar lugar no a «la» ética protestante sino, en todo caso, a «las»-diversaséticas protestantes. En esta línea, se ha pretendido que cuando en su título Weber mencionaba la ética protestante se refería más probablemente a la puritana o quizás incluso a la «puritana tardía» ${ }^{16} \mathrm{o}$, como mucho, a la «calvinista» (raíz de la puritana). En cualquier caso, no cabe duda de que Weber centraría su estudio en lo que denominó el «protestantismo ascético» y en el que considera incluidos calvinismo, pietismo, metodismo y baptismo ${ }^{17}$. En resumen, y sin intención de ser excesivamente severo con su planteamiento, podría afirmarse que Weber tomó la parte por el todo, introduciendo así una distorsión nada despreciable.

Por otro lado, Boltanski y Chiapelli (2011) han destacado que el origen de la expresión «espíritu del capitalismo» se encuentra en Sombart antes que en Weber y:

\footnotetext{
Horkheimer 2010, 76.

Horkheimer 2010, 77.

Tocqueville 1840, 20.

Weber 2009, 194.

Tawney 1926, 226.

Weber 2009, 108.
} 
nace (...) «de la conjunción del "espíritu fáustico” y del "espíritu burgués"», [y] toma un sentido muy diferente al que le dará Weber. El espíritu del capitalismo se encuentra en Sombart más centrado en el carácter demiúrgico del gran hombre de negocios [brasseur d'affaires], mientras que Weber insiste más sobre la ética del trabajo [besogne $]^{18}$.

Si bien Boltanski y Chiapello centran su definición de capitalismo en torno a «una exigencia [esto es, una meta en sí] de acumulación ilimitada de capital por medios formalmente pacíficos» ${ }^{19}$, lo cierto es que, más allá de la mera acumulación de capital, el término capitalismo posee gran cantidad de resonancias, de modo que resulta realmente complejo encontrar una definición que sea breve y suficientemente abarcadora a la vez. Casi podría afirmarse que cualquier definición que aquí se propusiera como punto de partida, podría ser, con razón, rebatida o, cuando menos, matizada. Hoy resulta posible, cuando no más correcto, hablar de «capitalismos» antes que de capitalismo. Así, el término capitalismo puede hacer referencia a la estratificación social que implica en base a las relaciones de producción, a determinadas formas de consumo y economía de mercado, a cierta forma de organización del trabajo, a la existencia de mercados financieros, etc. Por suerte, lo que aquí interesa es qué cosa entendiera Weber por capitalismo y su espíritu. En este sentido, al hablar del «espíritu» del capitalismo Weber parece hacer referencia a la presencia de reminiscencias o rasgos «evocadores» del protestantismo en la vida del capitalismo. En este sentido resulta bastante orientativa la definición que propusieran Boltanski y Chiapello (2011): «llamamos espíritu del capitalismo a la ideología que justifica el compromiso con el capitalismo» ${ }^{20}$, a "ese conjunto de creencias asociadas al orden capitalista que contribuyen a justificar este orden y a sostener, legitimándolos, los modos de acción y las disposiciones coherentes con él»» ${ }^{21}$.

Sea como fuere, no cabe duda de que el manejo de conceptos con un alto grado de abstracción y cuya proyección sobre el ordenamiento de la realidad (política o de otro tipo) es de difícil demarcación ha dado pie a interpretaciones muy variadas. Así, no resulta extraño encontrar interpretaciones de la tesis de Weber en el sentido no ya de un determinado rasgo peculiar del protestantismo que pudiera desarrollar cierta forma de economía más próspera sino, directamente, en términos de una «inferioridad del cristianismo romano respecto al protestantismo para construir economías capitalistas solventes» ${ }^{22}$, destacándose por ejemplo el hecho notorio de que «en los tres países en crisis [año 2012], las jerarquías católicas viven en un clamoroso paraíso fiscal». Una comprensión que, por otra parte, no es nada novedosa puesto que, ya en el siglo XVI, Maquiavelo había expresado que «aquellos países que son vecinos más cercanos de la Iglesia Romana, cabeza de nuestra fe, poseen menor devoción que el resto» pues «a través del mal ejemplo de la Curia romana el país [Italia] ha perdido todo sentimiento religioso y devoción, una pérdida que ha desembocado en infinitos desmanes y desordenes», concluyendo que «nosotros los italianos le debemos, pues, a la Iglesia y a los sacerdotes habernos convertido en

\footnotetext{
Boltanski y Chiapello 2011, 749 n.

Boltanski y Chiapello 2011, 35.

Boltanski y Chiapello 2011, 41.

Boltanski y Chiapello 2011, 45.

Bedoya 2012.
} 
pícaros e irreligiosos» ${ }^{23}$. Para no dejar dudas al respecto de una temprana «superioridad» de esta ética que años más tarde se denominaría protestante, añadía: «En Alemania, sin embargo, se ven prevalecer signos de excelencia y un espíritu religioso devoto entre las gentes, dando lugar a los muchos estados libres que se sostienen a sí mismos, con tan estricta observancia de sus leyes que nadie, sea dentro o fuera de sus muros, osa infringirlas» ${ }^{24}$. Por otro lado, resulta conveniente señalar que, si bien la obra de Weber ha resultado ser la más divulgada a este respecto, fue precisamente un católico bávaro, Johann Adam von Ickstatt, el que por primera vez pondría sobre la mesa, por cierto en clave crítica y con la intención de encontrarle algún remedio, la cuestión relativa a la manifiesta diferencia en el desarrollo económico alcanzado por las regiones protestantes frente a las católicas ${ }^{25}$.

Comprensiblemente, no es posible hablar de una aceptación unánime o de consenso en torno a la «explicación» propuesta por Weber a los datos recogidos por su alumno Offenbacher ${ }^{26}$ y que podría resumirse en una superioridad o una mayor adecuación, afinidad o compatibilidad de los rasgos culturales y/o actitudinales del protestantismo «ascético» en lo relativo a una vida económica más exitosa. A este respecto es posible destacar aquí las críticas llevadas a cabo por Besnard ${ }^{27}$, MacKinnon ${ }^{28}$ y Disselkamp ${ }^{29}$.

Se reitera aquí que queda lejos de las intenciones del presente trabajo el entrar a valorar lo acertado o no de la tesis que fuera propuesta por Weber con relación a un vínculo más o menos directo entre el surgimiento del capitalismo y ciertos rasgos propios del protestantismo. Tampoco se pretende llevar a cabo una reinterpretación más, a añadir a la miríada de ellas, de lo que Weber pretendió proponer -una cuestión que, por sí sola, ha llenado miles de páginas-. Se trata más bien de llevar a cabo una revisión de los fundamentos doctrinales que se sitúan alrededor de la cuestión, pero con la perspectiva que ofrece los más de cien años desde que dicha tesis fuera presentada y con ocasión de la celebración del 500 Aniversario de la Reforma Protestante. Al fijar este objetivo, no cabe duda de que será necesario abordar determinadas cuestiones más propias del análisis teológico, algo que, por otra parte, no debiera intimidar al investigador social menos especializado dado que, al fin y al cabo, y parafraseando lo que dijera Clemenceau con relación a la guerra y los militares: la teología trata de asuntos demasiado importantes como para dejárselos sólo a los teólogos.

\section{Capitalismo o mammonismo. Emprendimiento o codicia}

Una primera cuestión que es necesario tener presente al abordar la relación que pueda existir entre ética (sea protestante o de otra índole) y economía es que no debe

23 Machiavelli 1883, 56.

24 Machiavelli 1883, 166.

25 Nos referimos a su trabajo publicado en Salzburgo en 1773 bajo un pseudónimo que es toda una declaración de principios, Christian Friedrich Menschenfreund, y que llevaba por título Untersuchung der Frage: Warum ist der Wohlstand der protestantischen Länder sogar viel grösser als der katholischen? (Examen de la cuestión: ¿Por qué es la prosperidad de los países protestantes mucho mayor que la de los católicos?).

26 Offenbacher 1901.

27 Besnard 1970.

28 MacKinnon 1993.

29 Disselkamp 1994. 
equipararse la prosperidad económica con la adopción de determinado sistema económico, ya que, siendo la organización importante, esta no lo es todo. Hay otros factores que intervienen sobre el mayor o menor éxito económico en una nación, como puedan ser los de tipo cultural o la existencia o no de los recursos naturales indispensables. Por otro lado, ya el propio Weber destacó que no debía confundirse el afán desenfrenado de lucro o la mera codicia con el capitalismo. La codicia no es fruto del capitalismo, sino de la propia condición humana. Algo que desde el protestantismo, dado el propio origen de su doctrina y en concreto del profundo pesimismo antropológico transmitido por Lutero ${ }^{30}$, se ha de asumir como sobradamente admitido. Tal y como Weber señalara en su introducción ${ }^{31}$ :

"Ansia de beneficios" [Erwerbstrieb], "afán de lucro", por enriquecerse, por enriquecerse tanto como sea posible no tienen en sí apenas nada que ver con el capitalismo. Este afán se encontró y se encuentra en camareros, médicos, cocheros, artistas, prostitutas [Kokotten], funcionarios sobornables, soldados, ladrones, cruzados, asiduos a garitos [Spielhöllenbesuchern], mendigos: podría decirse: en "all sorts and conditions of men", de todas las épocas y de todos los países de la Tierra; allí donde hubo o haya la posibilidad objetiva para, de un modo u otro, aprovechar la oportunidad. Forma parte de la más elemental formación histórico-cultural, que esta ingenua concepción debiera abandonarse de una vez por todas; que la codicia ganancial sin límites no tiene lo más mínimo que ver con el capitalismo, menos aún con su "espíritu". En realidad, el capitalismo puede identificarse con la contención [Bändigung], o al menos con la moderación racional de este instinto irracional de lucro ${ }^{32}$.

En este sentido, si se revisa la doctrina de ambas confesiones, tanto la protestante como la católica, se aprecia claramente cómo no se ve con excesiva alegría un interés desmedido por la acumulación de riquezas. Al fin y al cabo, con ciertos matices con relación a la interpretación y al reconocimiento o no de ciertos libros como canónicos, ambas poseen, en gran medida, un mismo texto de «referencia»: La Biblia. Simplificando, podría decirse que la riqueza en sí misma no se entiende como motivo de condena pero que, desde el momento en que se hace de ésta un fin y la medida de todas las cosas y todos los actos -esto es, se idolatra-, se convierte en causa de condenación. En cualquier caso, la especial importancia de la cuestión queda expresada por su ubicuidad en los textos sagrados y, de este modo, sí se señala a la acumulación de riquezas como uno de los grandes males del mundo, uno de los grandes vicios del hombre. Resultaría tedioso citar aquí todas las referencias bíblicas que dan testimonio de ello. He aquí sólo algunas: «!Cuán difícilmente entrarán en el reino de Dios los que tienen riquezas!» (Mt 19, 23 y Mc 10, 23); «Le resulta más fácil a un camello ${ }^{33}$ pasar por el ojo de una aguja, que a un rico entrar en el reino de Dios» ( $\mathrm{Mc}$

30 Maestro 2016, 164-165.

31 Ha de recordarse a este respecto que La ética protestante y el «espíritu» del capitalismo no es sino la síntesis de dos trabajos publicados previamente en sendas revistas. Quizás sea por ello que dicha introducción se ha perdido en alguna de las traducciones al castellano.

32 Weber 1986, 4.

33 Es conocido que esta tradicional aunque algo disparatada traducción suele considerarse errónea, optándose hoy por considerar que se hacía referencia al término griego con que se conocía a las maromas con que se amarraban los barcos (kamilos). 
10, 25 y Mt 19, 23-24); «El que tiene dos túnicas, dé al que no tiene; y el que tiene qué comer, haga lo mismo» (Lc 3, 11); «Bienaventurados vosotros los pobres, porque vuestro es el reino de Dios» (Lc 6, 20); «porque raíz de todos los males es el amor al dinero» $(1 \mathrm{Tm} 6,10)$; «Sean vuestras costumbres sin avaricia, contentos con lo que tenéis ahora» (Heb 13,5); «porque donde está vuestro tesoro, allí estará también vuestro corazón» (Lc 12, 34 y Mt 6,21) de modo que «no podéis servir a Dios y a las riquezas» (Lc 16, 13 y Mt 6, 24). No ha de extrañar por tanto que recientemente, y parafraseando a Giovanni Papini ${ }^{34}$, el papa Francisco I haya caracterizado al dinero como «el estiércol del diablo» ${ }^{35}$. Es cierto que, frente a esta inequívoca interpretación, pueden sorprender determinados planteamientos de ascendencia calvinista referidos por Weber, y que podrían sintetizarse con la siguiente exhortación de Baxter: «Si (...) seguís el camino que reporta menos ganancias, os estáis oponiendo a uno de los fines de vuestra profesión (calling), os estáis negando a ser administradores (stewart) de Dios (...) Podéis trabajar para ser ricos para Dios» ${ }^{36}$ (énfasis en el original).

Con relación a la percepción religiosa de la riqueza, podría decirse que el dilema del capital -su pecado capital cabría decir-y el origen de la hostilidad que en ocasiones genera, podría explicarse por su desapego crónico hacia la auténtica riqueza: toda aquella que no consista en dinero. Algo que ha quedado sintetizado en el conocido adagio atribuido al emperador Vespasiano: «pecunia non olet $\rangle^{37}$. Frente a este planteamiento, resulta comprensible que haya quien entienda que la acumulación de riquezas nada tiene que ver con la moral (aunque, en realidad, esta tenga que ver con todo), sin embargo, no cabe duda de que un rasgo del capitalismo es el de desatender el origen y destino del capital, sirviendo lo mismo para financiar un hospital para refugiados que para financiar la guerra que los ha convertido en tales. Es quizás por ello que al cristiano debe resultarle difícil desentenderse de aquél bíblico «por sus frutos los conoceréis» (Mt 7,20) y considerar ambos fines (guerra y curación) de manera indistinta. En este sentido, se ha afirmado que «la rebelión de Lutero contra la Iglesia fue causada en parte por el hecho de que Roma poseía unas relaciones demasiado cercanas con estos capitalistas pre-Reforma [Médici, Fugger, etc.] $\rangle^{38}$.

Por otra parte, una cosa es el lucro y otra el lujo. Si lo primero puede llegar a ser una necesidad, lo segundo no. Si lo primero ha de ser necesariamente desarrollado por cualquier sistema económico (incluido el capitalismo), lo segundo no. Por otra parte, el lucro es perfectamente compatible con el bien común y, por tanto, una eventual virtud religiosa, mientras que el lujo no tanto. En este sentido, la ética protestante que se describe en Weber es la de una industriosidad y austeridad (buena factura y rechazo del despilfarro) que inevitablemente -y no como fin en sí- han de desembocar en un mayor beneficio. Así, ha llegado a hablarse de la sociedad de consumo como un claro contraejemplo de lo que se viene denominando la «ética protestante». Rifkin habla por ejemplo de «la metamorfosis del concepto de consumo desde el vicio hasta la virtud ${ }^{39}$, encuadrándola explícitamente en el abandono de «la ética protestante del trabajo, que había dominado (...) el ethos del americano de frontera»,

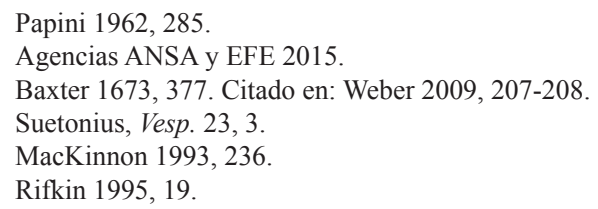


donde «la frugalidad [parsimony] y el sentido del ahorro eran piedras angulares» $\mathrm{y}$ «la virtud del autosacrificio continuaba dominando ante el señuelo [lure] de la satisfacción inmediata del mercado de consumo $»^{40}$. No se trata por tanto de que el protestante entienda su salvación o justificación en virtud de una consecución de mayores beneficios, sino de que el buen hacer inevitablemente (lógicamente) ha de generar una mayor riqueza. Lo que se haga con esta riqueza es otra cuestión y es ahí, y sólo ahí, donde intervendría en realidad una ética religiosa, en este caso, la protestante. Tal y como se intentará argumentar en el siguiente apartado, es una situación que podría explicarse en el contexto de la doctrina protestante con relación a las obras y la fe: para el protestante es la fe la que desemboca de manera inevitable -natural- en la realización de obras que pueden denominarse «buenas». De este modo, no son las obras el fin sino la consecuencia.

Todo lo anterior podría resumirse en términos religiosos en que una cosa es capitalismo y otra muy distinta mammonismo. En este sentido ha de reiterarse aquí que ni catolicismo ni protestantismo podrían admitir a éste último por cuanto equivaldría a situar al dinero en un lugar que solo le corresponde a Dios. Pese a ello, lo cierto es que existe cierta confusión, cuyo rastro puede seguirse hasta Aristóteles ${ }^{41}$, entre los conceptos de comercio o capitalismo -lo que él denominó oeconomía- y la mera crematística. Si la primera consiste en la simple administración del hogar y el intercambio de dinero por bienes de utilidad, la crematística sería el arte de acumular bienes o propiedades sin límite, siendo que Aristóteles considera la acumulación de dinero como fin y el intercambio de dinero por dinero (esto es, sin la mediación de la producción de bien alguno) una actividad antinatural que deshumaniza a quienes la practican. En esta misma línea, el hecho de que Lutero sacara de los monasterios a los monjes para que se pusieran a trabajar y formaran una familia podría entenderse como una clara preferencia por esas formas de trabajo que Aristóteles consideraba «naturales». Lutero consideraba la vida monástica -antítesis del espíritu emprendedor e industrioso- una forma asocial, egoísta e improductiva y, por tanto, poco acorde con los principios del cristianismo; algo así como una mera huída del mundo tal y como el Creador nos lo ha dado ${ }^{42}$. Lutero, a quien no puede acusarse de hablar sin conocimiento de causa -pasó veinte años de su vida en un monasterio-, llegó a afirmar: «[Los monjes] han ensalzado y proclamado impúdicamente su estado hipócrita y sus obras como la vida perfectísima, mientras que en verdad pensaban llevar un vida buena, dulce, sin cruz y sin paciencia. Y si han corrido a los conventos es para no tener necesidad de sufrir nada de nadie, ni hacer el bien a cualquier otro ${ }^{43}$. Se columbra aquí claramente cierto desprecio por una forma de vida que se entiende que, rehuyendo el esfuerzo y el perfeccionamiento que exigen el tener que ganarse la vida y mantener una familia, pretende evitar la realidad laboral y la vida económica en general. Se aprecia por tanto que, tras de la voluntad de cerrar monasterios, existe una razón claramente conectada con la política económica. Así, cuando un taller o una empresa quiebran, los trabajadores y sus familias se ven clara y directamente afectadas (algo que no suele ocurrir al cerrar un convento), algo que para Lutero conferiría una determinada forma de pensar y actuar, en otras palabras, algo que

\footnotetext{
Rifkin 1995, 19.

Aristóteles, Política I 8, 1256a ss.

Luther 1899, 564-669.

Luther 2000, 414.
} 
lleva asociados determinado régimen y forma de pensamiento económico. Siendo esta interpretación más o menos acertada, de lo que no cabe duda es de la transcendencia que este fenómeno habría tenido para la actividad económica de las naciones que abrazaron el protestantismo en cualquiera de sus formas, dado que la supresión del monacato, constituye -con matices- uno de los escasos rasgos comunes de las diversas formas de protestantismo.

\section{El cuestionamiento de las obras como fundamento de la ética protestante}

Uno de los rasgos más destacados del protestantismo es el de la llamada justificación por la fe, según la cual se viene a considerar al ser humano tan extremadamente imperfecto que resulta inconcebible que pueda alcanzar la salvación en base a sus propias obras. Se trata de una cuestión realmente compleja y con una apariencia verdaderamente contradictoria. No obstante, debido a sus implicaciones, de gran calado, resulta aconsejable detenerse a analizarla con algo de detalle aquí.

Una de las razones que se sitúan en el origen de esta doctrina es que, para el protestantismo, otorgar centralidad a las obras es otorgársela al hombre y quitársela así a un Dios que es omnipotente: « $¿ \mathrm{O}$ no tiene potestad el alfarero sobre el barro?» (Rm $9,21)$. Así, son diversos los pasajes de la Biblia que han dado sustento a esta doctrina, siendo de hecho un planteamiento que, al margen de los matices que puedan introducirse ${ }^{44}$, arranca de la mano de uno de los principales padres de la propia Iglesia católica, Agustín de Hipona. Se advierte aquí uno de los grandes -y tempranos- debates dentro del cristianismo, cual es el de monergismo frente a sinergismo y que se refiere, en esencia, a la cuestión sobre de quién dependa la salvación: si únicamente de Dios o si también del ser humano. Por otro lado, la capacidad de las obras para lograr la gracia de Dios es algo que, con posterioridad a Agustín pero antes que Lutero, ya había sido cuestionado por el Maestro Eckhart: «Todo lo que hagas en tus obras debes cumplirlo únicamente por el amor de Dios y mantenerte tan vacío de todo como vacía es la nada» ${ }^{45}$; «mercaderes son todos aquellos (...) a quienes les gustaría (...) hacer buenas obras (...) con el fin de que Nuestro Señor les dé algo a cambio» ${ }^{46}$. Yendo más lejos, ya el propio Eckhart había defendido que «toda oración y obras buenas no valen nada, porque Dios no las tiene en cuenta $»^{47}$. Una doctrina que, comprensiblemente, sería condenada en 1329 por la bula In agro dominico de Juan XXII.

Como se ha dicho, la clave sobre la que se apoya toda la teoría del solifidianismo es una comprensión del hombre cruelmente pesimista y compartida por Lutero. En cierto modo, el cuestionamiento de las obras que lleva a cabo Lutero evoca aquella especie de horror religiosus para el cual Kierkegaard escogió el término danés anfægtelse ${ }^{48}$. De hecho, en su Ejercitación del cristianismo, Kierkegaard consideraría «muy luterano» el hecho de que «solamente la conciencia del pecado puede empujarte (...) a este terror»; «sólo la conciencia del pecado garantiza el absoluto respeto

44 A este respecto resulta especialmente interesante el capítulo dedicado al semipelagianismo en Sproul, 1997, 69-86.

45 Maestro Eckhart 2011a, 55.

46 Maestro Eckhart 2011a, 54.

47 Maestro Eckhart 2011b, 172.

48 Kierkegaard 1843, 81. 
[que exige el cristianismo]», de manera que «la única puerta de entrada al cristianismo es la conciencia del pecado; y todo otro camino para querer introducirse en él es pecado de lesa majestad contra el cristianismo» ${ }^{49}$. No debe olvidarse que Lutero es un monje agustino, quedando así a priori bajo la influencia de ese pesimismo antropológico antipelagiano de Agustín de Hipona según el cual el hombre (la massa damnata) siempre actúa sometido al lastre del pecado original y de su naturaleza tendente al mal. Una doctrina que es posible encontrar en Del espiritu y la letra:

La gracia (...) no es dada según los méritos de las obras, sino gratuitamente (...) no será justificado por la ley hombre alguno en el acatamiento de Dios [Rm 3, 20]. Porque puede simularse esta justicia delante de los hombres, pero no delante de aquel que es el escudriñador del corazón mismo y de la voluntad más secreta ${ }^{50}$.

Así, no es que el hombre esté marcado por el pecado original sino que todo él es pecado, de tal modo que, desde la perspectiva de Lutero, bien pudiera caracterizarse al ser humano no ya como aquella «voluntad» de Schopenhauer o Nietzsche sino como una auténtica «concupiscencia ambulante». De este modo, podría decirse que el pecado original del hombre lo constituye su misma naturaleza humana, siendo que, como expresara Calderón, «el delito mayor del hombre es haber nacido» ${ }^{51}$. En consonancia con esto, Lutero niega el valor de la voluntad humana como medio a través del cual alcanzar la salvación, algo que desarrolla en su De servo arbitrio ${ }^{52}$.

Por otra parte, Lutero había sido formado en Erfurt y, por tanto, su pensamiento tuvo que recibir la influencia del nominalismo (la «vía moderna», como la llamaban), de acuerdo con el cual resulta imposible acceder a la realidad (y por ende a Dios y a su verdad revelada) a través de la razón, quedando por ello exclusivamente a expensas de la fe. De hecho, el que probablemente sea el máximo representante del nominalismo, Guillermo de Ockham, había afirmado: «nada le obliga a Dios a otorgar a cualquiera la vida eterna» ${ }^{53}$. Así, es la gracia divina la que salva y no las obras humanas, que en sí son pecado. Sucede entonces que, en palabras de Bloch, «según Lutero (...) el libre albedrío (...) sólo puede sustentar aspiraciones egoístas $\rangle^{54}$. Lutero considera que con ello da una lectura más fecunda al poner a las buenas obras en su sitio, esto es, no como la causa sino como la consecuencia de una fe verdadera: «una casa bien o mal hecha no hacen a un buen o mal carpintero, sino que según sea el carpintero, así será la casa» ${ }^{55}$. Las buenas obras surgen de manera natural como expresión de gratitud y amor a Dios: «Estas dos sentencias son, por consiguiente, ciertas. Primera: "Las obras buenas y justas jamás hacen al hombre bueno y justo, sino que el hombre bueno y justo realiza obras buenas y justas". Segunda: "Las malas obras nunca hacen al hombre malo, sino que el hombre malo ejecuta malas obras" $>{ }^{56}$. De este modo, el protestantismo no entiende el pecado como el acto aislado que aparenta ser, sino en su dimensión más global, como un alejamiento de la fe que es

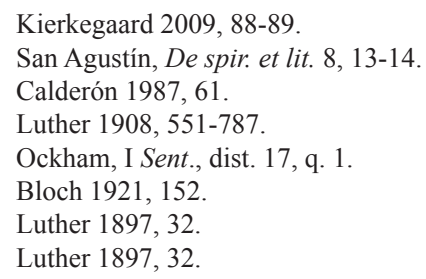


el que se sitúa en su origen: «la fe única (...) no nos convierte en ociosos o malhechores [übell], sino antes bien en hombres que no necesitan obra alguna para obtener la justificación y salvación» ${ }^{57}$. Al fin y al cabo, su pesimista percepción del hombre, nos dice que todos somos pecadores; que el pecado resulta inevitable. De aquí surge el tan tergiversado «sé pecador y peca fuerte» que Lutero escribiría a Melanchthon ${ }^{58}$.

Mucho se le ha criticado a Lutero esta forma-demasiado intrépida-de ver el «ser en el mundo» del cristiano (pues de eso se trata, ni más ni menos). Una crítica que podría resumirse con lo sostenido por Johann Adam Möhler: «cuanto más se exagere al fijar la medida de la culpabilidad objetiva en que se ve implicado el sujeto sin haber contraído culpa personal, tanto más decrecen las proporciones del mal subjetivo que efectivamente se cometió, y la naturaleza humana carga asimismo con la culpa contraída por la persona» ${ }^{59}$ (el énfasis ha sido añadido). Por su parte, ya en tiempos de Lutero, Erasmo había invocado a los mandamientos para defender el libre albedrío, si bien con un razonamiento no demasiado elaborado: si Dios no ha concedido al hombre el libre albedrío, ¿para qué le señala los mandamientos? ¿Qué sentido tendrían? Para ello, Erasmo se apoyaba fundamentalmente en el Eclesiástico (un libro que Lutero consideraba apócrifo y al que no le han faltado críticos incluso en la Iglesia católica ${ }^{60}$ ): «Dios creó al hombre al principio y le dio libertad de tomar sus decisiones. Si quieres, puedes cumplir lo que él manda, y puedes ser fiel haciendo lo que le gusta. Delante de ti tienes fuego y agua; escoge lo que quieras» (Eclo 15, 14-16).

Lo cierto es que parece estarse ante una de esas guerras de «trinchera» (teológica) tan habituales en el ámbito de la religión revelada y que sólo parece ser posible resolver apelando a la mejor retórica o sofística desplegada. De hecho, se trata de una problemática que recuerda bastante a la conocida paradoja de Newcomb (ese juego en el que, al existir un jugador capaz de predecir el futuro, la posibilidad del libre albedrío queda anulada). En cualquier caso, y siendo una doctrina que se corría el peligro de que fuera malinterpretada, ya reformadores como Melanchthon se sintieron abiertamente preocupados por las consecuencias que pudiera tener. Sin duda, Melanchthon tenía en mente los acontecimientos acaecidos durante la Guerra de los Campesinos, cuando gentes que se tenían por devotas parecían sentirse autorizadas a todo tipo de desmanes sin que, aparentemente, su puesto en el paraíso -ya «garantizado» por la sola fe- pudiera correr peligro ${ }^{61}$. Se ha afirmado a este respecto que «si se hubieran aplicado estrictamente las premisas teológicas de este tipo, habrían reducido cualquier proyecto educativo ad absurdum ${ }^{62}$. Quizás por ello surgiría la doctrina luterana (que no calvinista, y por tanto algo apartada de la tesis weberiana) de la gratia amissibilis o «gracia enajenable».

Sea como fuere, también es cierto que esta incomprensión devenida crítica ha pasado por alto que, de lo que realmente habla Lutero, no es de si ha de buscarse o no hacer buenas obras: «el hombre no puede prescindir de las obras en el trato con sus semejantes» ${ }^{63}$. Esto es algo que dejó bien claro cuando manifestó: «Responde-

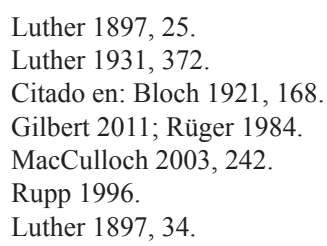


remos a todos aquellos que se enojan (...) y suelen exclamar: "Está bien: si la fe ya lo es todo y por sí sola basta para la justificación, ¿por qué han sido ordenadas las buenas obras? Vivamos, pues, alegres y confiados y sin hacer nada". No, querido hermano, eso es un error» ${ }^{64}$. Como ya se ha adelantado, de lo que se trata es del «espíritu» o la actitud vital que se adivina tras estas obras y no de las obras consideradas de manera aislada. La verdadera fe se muestra así como una de las manifestaciones más profundamente trascendentales de la libertad humana, pues no se limita a adoptar una simple creencia sino a vivir conforme a ella -también en el ámbito laboral o económico-, «pues quien cumple el primer mandamiento cumplirá también segura y fácilmente los demás. Las obras son, por el contrario, cosa muerta» y «es un discurso peligroso y oscuro [finstere] cuando se enseña a cumplir los mandamientos con obras [recuérdese que es la época de las indulgencias], toda vez que el cumplimiento ha de ocurrir a través de la fe antes de cualquier obra y las obras siguen a su cumplimiento» ${ }^{65}$; «Quien haya entendido esto podrá vivir fácilmente en medio [«a pesar», parece querer decir Lutero] de los innumerables preceptos y leyes del Papa, los obispos, los monasterios, los conventos, los príncipes y señores ${ }^{66}$.

En definitiva, lo que Lutero defiende es que las obras no cuentan nada si se las compara con la actitud cotidiana, ese «ser en el mundo» que es la fe. Es por ello que se ha dicho que «la devoción protestante es individual; y es como aquél doméstica; es una religiosidad privada ${ }^{67}$, algo que conecta con aquella comprensión marxiana que alegaba:

Lutero ha vencido la servidumbre de la devoción, porque ha puesto en su lugar la servidumbre por convicción. Ha quebrantado la fe en la autoridad, porque ha restaurado la autoridad de la fe. Ha transformado a los párrocos en laicos, porque ha transformado a los laicos en párrocos. Ha liberado a los hombres de la religiosidad exterior, porque ha llevado la religiosidad a su interior. Ha emancipado el cuerpo de las cadenas, porque ha encadenado el corazón ${ }^{68}$.

Más aún, se ha llegado a afirmar que «Marx se tiene por un segundo Lutero» ${ }^{69}, \mathrm{y}$ es que la anterior cita continuaba diciendo: «si el protestantismo no fue la verdadera solución, sí fue el verdadero planteamiento de la tarea. Ahora, ya no se trataba de la lucha del seglar con el cura fuera de él, sino de la lucha con su propio cura interior, con su naturaleza clerical». En este sentido, esta religiosidad protestante recuerda a aquella metamorfosis del espíritu desde el «tú debes» hacia el «yo quiero» que propusiera Nietzsche ${ }^{70}$. Mientras el catolicismo sería más un «tú debes», esto es, una conducta más dirigida desde fuera, el protestantismo sería más un «yo debo», una conducta guiada por la propia conciencia y, por ello, verdaderamente interiorizada; aquél «oculto estado policial» ${ }^{71}$ del que hablaría Stirner. 
Se ha escogido aquí la cuestión de la sola fe protestante en el contexto del análisis de la tesis de Weber entorno al capitalismo por cuanto se trata de uno de los rasgos protestantes con una más clara proyección sobre la vida cotidiana -también la económica- del mundo protestante. No pocos autores han destacado la conexión con la vida económica de ésta y otras virtudes «protestantes» como puedan ser el ascetismo secular, el individualismo, las éticas del tiempo y del trabajo, la racionalización y un comportamiento dirigido a la meta. Sea como fuere, se ha argumentado que el protestantismo ha repensado el trabajo como un deber que beneficia tanto al individuo como a la sociedad en su conjunto, de manera que el antiguo concepto católico de buenas obras quedó transformado en la obligación de trabajar con diligencia como signo de la gracia divina. Así, mientras que pareciera que el catolicismo ha entendido el trabajo únicamente desde la óptica de aquella maldición bíblica, «te ganarás el pan con el sudor de tu frente» $(\mathrm{Gn} 3,19)$, para el protestantismo parece que la primera obligación es la de desempeñar bien el propio oficio, algo para lo que se ha sido llamado por Dios. Esta es una concepción que Weber ${ }^{72}$ desarrolla a propósito de las singularidades propias del término alemán Beruf, con el cual se designa de manera indistinta a la vocación y a la profesión. De este modo, se entendería que haya autores para los que la peculiar actitud del protestantismo para con las obras ha de traducirse inevitablemente en una forma de ética específica que ha de proyectarse necesariamente en la actividad económica.

En clara conexión con la doctrina de la sola fe y con esta interpretación del éxito profesional como signo de la gracia divina y, por ende, como nuevo vínculo entre doctrina religiosa y económica, estaría la cuestión de la predestinación, también central en el pensamiento protestante (a decir verdad, en el calvinista). El fundamento bíblico de esta doctrina suele buscarse en la carta de Pablo a los Efesios, si bien suelen citarse muchos otros: «Según nos escogió antes de la fundación del mundo, (...) habiéndonos predestinado para ser adoptados hijos suyos por medio de Jesucristo, según el puro afecto de su voluntad» (Ef 1, 4-5). Para ser estrictos, ha de recordarse que, tal y como se ha señalado, la doctrina de la predestinación no es de concepción luterana sino una percepción calvinista que queda encuadrada en lo que se ha denominado teología negativa o apofática, una forma de teología que se remonta al siglo II d. C. con Clemente de Alejandría ${ }^{73}$ y que viene a afirmar que resulta más fácil conocer a Dios desde una perspectiva negativa (aquella que aborda lo que no es Dios) que desde una positiva. Siendo Dios hyperagnostos (ultrainteligible) e hyperousios (supraesencial) en el sentido de Juan Escoto Eriúgena ${ }^{74}$ y la nuestra una docta ignorancia ${ }^{75}$, Pseudo Dionisio Areopagita ya había expresado que «si alguno al ver a Dios, comprende lo que ve, no es a Dios mismo a quien ha visto (...). Pues Él (...) sobrepasa todo ser y conocer» ${ }^{76}$. En este sentido, la teología negativa encaja mejor con cierta concepción mística de Dios, contrastando con la fórmula más acostumbrada de la teología católica moderna, que admite un acercamiento racional, más escolástico o aristotélico, a la figura de Dios. La predestinación se alinea así con aquél socrático «sólo sé que nada sé» con el que se intenta poner un kantiano «coto» a la razón o, más exactamente, a los excesos racionalizadores en teología.

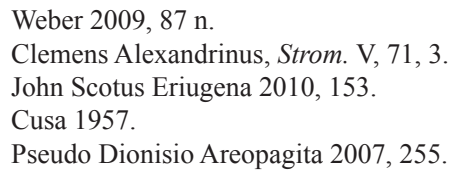


Sea como fuere, el debate fundamental residiría aquí en si el binomio sola fepredestinación constituye una comprensión verdaderamente cotidiana (absolutamente interiorizada) para el protestantismo o si más bien se trata de una doctrina que se acepta pero sin intención de racionalizarla hasta el extremo de pretender encontrar en ella la «explicación» a los acontecimientos que puedan acaecerle a un individuo. A este respecto, ya el propio Lutero advirtió: «algunos piensan tener a Dios y a todas las cosas en abundancia, cuando poseen dinero y bienes (...) tal persona tiene ya también a un Dios que se llama Mammón $»^{77}$. En suma, habría que determinar hasta qué punto, y de acuerdo con Weber, un protestante se considera salvo por el mero hecho de vivir con prosperidad económica. Y es que la doctrina habla de sola fide, no de sola prosperidad, siendo que cualquier conexión entre la salvación y el éxito económico de un individuo resulta desprovista de sentido y totalmente fuera de lugar. No resulta por ello demasiado acertada aquella lectura de Bloch según la cual para el protestantismo «la autodisciplina es la garantía subjetiva de la certidumbre de que uno se salva, mientras que el éxito constituye la garantía objetiva» ${ }^{78}$. Es sólo en la conciencia del deber, en esta severa autodisciplina diaria que se ha dado en llamar ascetismo secular o, en palabras de Weber ${ }^{79}$, intramundano (innerweltliche) donde el protestante puede percibir algún indicio o señal de haber sido elegido por Dios para la salvación. Y es que, como dijo Carlyle, «un hombre que no conoce el rigor, tampoco conoce la compasión $»^{80}$.

\section{La tesis de Weber a la luz del encuadre propuesto}

Desde que Weber publicara su obra, han sido multitud los trabajos que han criticado una interpretación de ésta en el sentido de un origen del capitalismo situado netamente en determinados rasgos del protestantismo y, en concreto, del calvinismo. Pese a ello, sigue siendo habitual encontrar referencias al trabajo de Weber (especialmente en los medios de comunicación más generalistas) que entienden o defienden una conexión directa entre el protestantismo y el capitalismo y, más aún, entre aquél y una mayor prosperidad económica. Todo ello a pesar de que Weber jamás planteó su tesis en términos de monocausalidad o génesis directa, sino en la forma de una mera relación, se ha dicho, de $\langle f e e d b a c k\rangle^{81}$. De este modo, resulta interesante destacar cómo algún medio de comunicación ha citado trabajos situados en la estela de Weber aún cuando no presenten ningún resultado concluyente o incluso hayan aplicado la tesis de Weber sobre un ámbito geográfico que no está en consonancia con el propuesto por Weber, quien se centró en puritanismo y calvinismo. Es el caso de Cantoni (2015), quien indica sin reparos que «la inmensa mayoría de territorios considerados en el análisis son luteranos $\gg{ }^{82}$. Este matiz, que pudiera parecer baladí, resulta capital si lo que se pretende es afirmar nada menos que se ha logrado «matar al padre de la sociología moderna $»^{83}$ o que así se «desmonta con tanto cuidado como

\footnotetext{
Luther 2000, 382 .

Bloch 1921, 149-150.

Weber 2009.

Carlyle 1985, 117.

Forcese 1968, 193.

Cantoni 2015, 573.

Sánchez-Vallejo 2010.
} 
rigor la tesis clásica de que los protestantes son más eficientes e industriosos que los católicos $\gg{ }^{84}$. Y ello a pesar de que en este caso lo único que Cantoni se atreve a afirmar es que «protestantes y católicos podrían no haber sido, después de todo, tan distintos en su rendimiento económico ${ }^{85}$, pero que en algún medio se interpreta como que «la relación entre religión y desempeño económico bien pudiera ser exactamente la contraria ${ }^{86}$ (el énfasis es nuestro).

Casi podría decirse que las proposiciones de Weber han dado lugar a un auténtico género científico propio mediante el cual cualquier nueva información de carácter socioeconómico que es recabada es puesta al servicio de la verificación o el rechazo de la tesis principal de Weber. Sin querer llevar a cabo aquí una revisión de las principales aportaciones en este sentido (para ello puede recomendarse acudir a la historiografía que ha llevado a cabo Gil Villegas ${ }^{87}$ ), si consideramos que la revisión de algunos ejemplos puede ilustrar de un modo muy esclarecedor el tipo de problemática a que ha dado pie la obra de Weber. Así, surgen con regularidad trabajos que parecen inferir de las conclusiones de Weber (si es que realmente puede hablarse de conclusiones) una correlación estadística con tan sólo comparar alguna variable que pueda tomarse como proxy del crecimiento económico (ya sea el tamaño de las ciudades ${ }^{88}$, la renta per cápita ${ }^{89} \mathrm{u}$ otro) o incluso de la actitud hacia el trabajo $^{90}$ con algún asombroso índice de filiación religiosa. Tales estudios no hacen sino seguir, con más o menos lógica, el camino marcado por Weber cuando en su trabajo utilizara una serie de sencillas tablas estadísticas, recopiladas por su discípulo Martin Offenbacher ${ }^{91}$, en las que se cruzaban los porcentajes de ocupación de puestos como directivo con las principales confesiones de Alemania (judía, católica y protestante) como toda base empírica. En realidad, tanto aquellos datos como los que puedan utilizarse hoy puede que revelen determinada coyuntura, puede que incluso avalada por sorprendentes valores del coeficiente de determinación, pero en ningún caso constatan ni demuestran nada, dado que no parece tener mucho sentido la búsqueda de tal correlación cuando se trata de una cuestión para la cual los resultados obtenidos difícilmente podrán garantizar una explicación. Esta es una problemática que recuerda la curiosa broma del geógrafo Richard Florida acerca de la vinculación positiva que podía observarse entre el número de bandas de heavy metal y la riqueza de un país ${ }^{92}$. Al fin y al cabo, si Weber hubiese estado de acuerdo con tan estricta lectura de los datos socioeconómicos como apoyo indiscutible de su teoría, esta habría estado más en la línea de la que unos años más tarde propondría

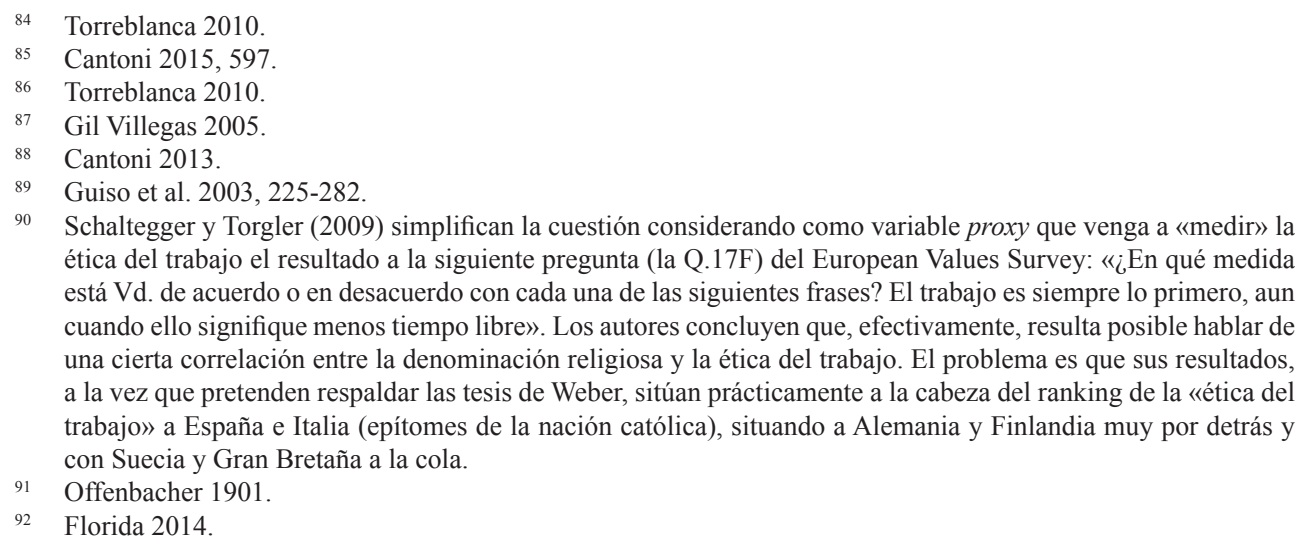
está Vd. de acuerdo o en desacuerdo con cada una de las siguientes frases? El trabajo es siempre lo primero, aun cuando ello signifique menos tiempo libre». Los autores concluyen que, efectivamente, resulta posible hablar de una cierta correlación entre la denominación religiosa y la ética del trabajo. El problema es que sus resultados, a la vez que pretenden respaldar las tesis de Weber, sitúan prácticamente a la cabeza del ranking de la «ética del trabajo» a España e Italia (epítomes de la nación católica), situando a Alemania y Finlandia muy por detrás y con Suecia y Gran Bretaña a la cola.

91 Offenbacher 1901.

92 Florida 2014. 
Sombart ${ }^{93}$, concluyendo que el judaísmo constituye la máxima expresión del desarrollo económico, pues los datos de Weber situaban a éstos claramente (cuatro veces) por delante de católicos y protestantes: «En Baden, por ejemplo, se llegó en el año 1897 a que cada 1000 evangélicos pagaran 954.060 marcos de impuesto sobre las rentas de capital, cada 1000 católicos pagaban 589.000 marcos. Por supuesto, los judíos desfilaban con mucho a la cabeza, con más de 4 millones por cada $1000 »^{94}$. Por su parte, para Sombart:

Las nuevas formas de la organización industrial [se refiere en esencia a la Bolsa de Valores] habían nacido de un espíritu completamente particular y sólo pueden entenderse como el resultado [Ausflüsse] de este particular "espíritu" (...) Nuestra economía nacional no sólo ha coexperimentado [miterfahren] su carácter con los judíos, sino que una parte importante de la esencia de su estructura exterior les es debida, lo mismo que el mecanismo interior de la moderna vida económica o los principios económicos rectores; lo que puede denominarse el espíritu de la vida económica o quizás incluso más apropiadamente el credo económico [Wirtschaftsgesinnung], es debido en su mayor parte a la influencia judía ${ }^{95}$.

En este sentido, Sombart prefirió limitar el papel del judaísmo a la creación de uno de los capitalismos, aquel que gira en torno a la especulación financiera ${ }^{96}$ (a la que Weber, amablemente, había denominado capitalismo «aventurero» $\left.{ }^{97}\right)$. Y es que para Sombart, quien conecta así sus conclusiones con las de Weber, las éticas del puritanismo y el judaísmo son en la práctica equivalentes: «El puritanismo es un judaísmo» ${ }^{98}$; «lo que Weber atribuyó al puritanismo (...) fue un logro del judaísmo (...) [ya que] dado que otros sistemas religiosos, como el puritanismo, han ejercido su influencia en la conformación de la vida económica, tanto más podríamos continuarlo afirmando en el caso del judaísmo, pues jamás hubo un pueblo civilizado para el que la religión haya significado tanto como para los judíos $\rangle^{99}$.

Llegados a este punto, otro aspecto, ya comentado aquí por su significación y por ser en ocasiones pasado por alto, es que Weber se esforzó por hablar no del capitalismo sino del «espíritu» del capitalismo, existiendo una notable diferencia entre ambos conceptos. Para empeorar las cosas, a menudo se pierden las comillas que Weber se cuidó de añadir al término «espíritu» en el título de su trabajo. Unas comillas que matizan y contextualizan de manera clara aquello de lo que Weber quiere hablar (o quizás sea mejor decir, aquello de lo que Weber no quiere o no se decide a hablar). La magnitud de esta aparentemente intrascendente cuestión es algo que queda muy claro cuando el propio Weber advierte de que «por "espíritu" del capitalismo no se puede o no se debe entender necesariamente sólo lo que nosotros nos representemos de él como lo "esencial"» (énfasis en el original). Por otro lado, Weber fue muy insistente a la hora de distinguir entre «espíritu» del capitalismo, capitalismo inicial o «pre-moderno» y capitalismo «actual». Así, se ha dicho que Weber entiende por

\footnotetext{
Sombart 1911.

Weber 1986, $17 \mathrm{n}$.

Sombart 1911, 136.

Attali 2011, 338.

Weber 1986, 10.

Sombart 1911, 293.

Sombart 1911, 226.
} 
«espíritu» del capitalismo a «la mentalidad o actitud que aspira sistemática y profesionalmente al lucro por el lucro» ${ }^{100}$. De lo que no cabe duda es de la evidente distinción que establece Weber entre lo que es el «desarrollo capitalista» ${ }^{101}-\mathrm{y}$, con éste, el capitalismo actual-y lo que constituyen sus raíces. A estas últimas es a lo que Weber hace referencia cuando habla del «espíritu» del capitalismo: a la cosmovisión que operó en su nacimiento y primeros tiempos y que no tiene por qué asemejarse a la hoy imperante. En este sentido, si bien Weber jamás se mostró excesivamente crítico con respecto al capitalismo de su tiempo, lo cierto es que tampoco llegó a conocer el capitalismo tal y como opera en la actualidad y que sigue siendo asociado, de un modo no demasiado circunspecto, con una cierta ética protestante. Sea como fuere, resulta francamente difícil argumentar a favor de la tesis de Weber cuando uno lee al propio Lutero declarar: «debes fijarte como norma el no buscar, en estos asuntos comerciales, más que tu subsistencia decente» ${ }^{102}$; «en el caso de que, sin saberlo ni quererlo, ganes un poco más de la cuenta, inclúyelo en el Padrenuestro, en que rezamos: "Perdónanos nuestras deudas" $\rangle{ }^{103}$. Por otro lado, Lutero es muy claro en cuanto que «según el derecho divino, cuando se presta o se vende a crédito, no se debería hacer pagar más caro que al contado» ${ }^{104}$, no escatimando en calificativos hacia esos «degolladores y estranguladores (...) que pasan por gente importante y hábil»» ${ }^{105} \mathrm{ni}$ hacia sus «pérfidas artimañas de la codicia» ${ }^{106}$, a saber, la especulación ${ }^{107}$, los monopolios $^{108}$ y los cárteles ${ }^{109}$. Para ellos, el ruiseñor de Wittenberg aconseja: «dejadles morir como perros y que el diablo les devore en cuerpo y alma, no les dejéis recibir el sacramento ni el bautismo en una sola comunidad cristiana ${ }^{110}$. ¿Dónde se dan aquí la mano la «ética protestante» y el «espíritu del capitalismo»? Parece aquí más adecuado considerar a Lutero como un precursor de Proudhon cuando defendía que el capital nunca debería ser considerado productivo por sí solo ${ }^{111}$. De hecho, no resulta extraño que fuese Marx y no otro quien se refiriese a Lutero como «el más antiguo economista alemán» ${ }^{112}$.

Hechas estas aclaraciones, de lo que no cabe duda es de la importancia específica que tiene en el protestantismo la extensión de la religiosidad hasta el plano laboral. Dicha circunstancia es la que Weber trató de describir apelando a John Wesley cuando asegurara que «la religión debe necesariamente producir tanto laboriosidad (industry) como espíritu de ahorro (frugality) $»{ }^{113}$. La cuestión residiría no obstante en averiguar si el protestante realmente admite como «verdad de fe» que, tal y como proseguía Wesley, «éstas [laboriosidad y espíritu de ahorro] no pueden sino generar riqueza». Y es que quizás resida en esta desafortunada asociación entre laboriosidad

\footnotetext{
100 Abellán 2009, 17

101 Weber 2009, 64.

102 Luther 2009, 77.

103 Luther 2009, 77-78.

104 Luther 2009, 93.

105 Luther 2009, 99.

106 Luther 2009, 93.

107 Luther 2009, 93.

108 Luther 2009, 93-94.

109 Luther 2009, 99-100.

110 Luther 1914, 421-422.

111 Proudhon 1983, 143 y 163.

112 Marx 2007, 147.

113 Wesley 1786, 322.
} 
y riqueza una primera carencia de la argumentación tanto de Wesley como de Weber. Ciertamente, puede que en un mundo ideal, sin endogamia, nepotismo u otras formas de injusticia esto pudiera ser así y la riqueza fuera necesariamente indicio de laboriosidad y frugalidad, pero nuestro mundo dista de ser así. No en vano el propio Lutero se sintió forzado a señalar: «no hay ningún mérito cristiano en comprar algo, poseerlo por herencia u obtenerlo de otra manera que sea honrada ${ }^{114}$. En definitiva, nada tienen que ver las opciones de prosperar que en base a sus méritos y cualificaciones pudiera tener un trabajador en tiempos de Weber con las que ése mismo trabajador pudiera encontrar hoy. Tal y como han señalado Boltanski y Chiapello precisamente con relación al espíritu del capitalismo:

Hoy, la seguridad proporcionada por los certificados académicos ha disminuido, las pensiones de jubilación se encuentran amenazadas y las posibilidades de promoción ya no están garantizadas. La capacidad de movilización del "segundo espíritu" [aquel imperante hoy y que los autores describen como profundamente despersonalizado] está en cuestión, mientras que las formas de acumulación se han visto de nuevo profundamente transformadas ${ }^{115}$.

En consecuencia, es posible que determinada forma de religiosidad nos conceda una gran riqueza interior, pero un asunto muy distinto son sus efectos en forma de una riqueza «exterior».

\section{Síntesis conclusiva}

Una de las primeras conclusiones que pueden derivarse de la situación expuesta aquí en torno a la tesis de Weber es que no deja de sorprender cómo es posible que, siendo una teoría tan popular, se haya desplegado en torno a ella tanta confusión -aunque quizás sea precisamente por ello-. Por otra parte, y a tenor del recorrido seguido desde su publicación hasta la actualidad, cabe destacar cómo el trabajo de Weber parece haber proporcionado, voluntaria o involuntariamente, un argumento de apariencia científica a aquellos que postulan por un hipotético retraso económico o incluso unos mayores niveles de corrupción en aquellos países a los que, con mayor o menor acierto, se denomina «católicos». Dicho amparo ha tenido una importancia significativa si nos atenemos a la frecuencia con que es referido. Y es que la sombra de Weber es alargada. La importancia de sus aportes metodológicos en el campo de la sociología (tipos ideales, concepción comprensiva, etc.) sin duda contribuye a ello. Sin embargo, ni los argumentos a favor, ni aquellos que han buscado refutarlo, han sido hasta la fecha excesivamente concluyentes. En este sentido, se trata de un debate que, si bien quizás no haya motivos suficientes para calificarlo de estéril, ofrece pocas posibilidades para llevar a cabo lo que Popper denominaría su «falsación» por lo que, de acuerdo con sus planteamientos, resultaría una materia muy próxima a lo que él entendió como pseudociencia. En resumen, la tesis de Weber jamás ha quedado demostrada y por tanto, en el mejor de los casos, no puede ser considerada cierta o científicamente avalada y, en el peor, constituye una falsedad o

\footnotetext{
114 Luther 2009, 51.

115 Boltanski y Chiapello 2011, 57.
} 
un mero prejuicio. Puede que algo más elaborado o disimulado (algo que lo haría más peligroso), pero prejuicio al fin. Dicho esto, y sin poder admitirse de manera concluyente una estrecha conexión entre ambas dimensiones -desarrollo económico y desarrollo religioso-, sí ha de reconocerse que la hipótesis de Weber, permaneciendo como tal, presenta suficientes visos de verosimilitud como para que unas economías se confronten con otras a fin de evitar los errores que puedan advertir y poner en práctica aquellas destrezas o aciertos sociales que sean más manifiestos. Si no fuera porque se trata de hacer ciencia y no de mera narrativa, con relación a la tesis de Weber uno se sentiría tentado a decir aquello de que «se non è vero, è ben trovato». Pero se trata de hacer ciencia.

En definitiva, se aprecia cómo el trabajo de Weber sigue constituyendo a día de hoy un excelente material para la investigación y, con mayor motivo, para la reflexión. En este sentido, una supuesta relación de causalidad entre protestantismo y capitalismo queda ya completamente fuera de lugar, no pudiendo irse más allá de percibir aquellas «afinidades electivas» de las que hablaba Weber. Quizás esta sea la razón por la que, por más que se recaben nuevos datos o incluso se descubran sorprendentes indicadores de correlación estadística, un siglo después continua siendo imposible confirmar la principal tesis de Weber. ¿Se trata entonces de mera recreación o palabrería? Tampoco. Pero lo cierto es que, hasta el momento, cualquier empeño por confirmar o refutar su tesis de manera concluyente sólo parece quedar explicado por intereses espurios que nada tienen que ver con la ciencia sino más bien con el sectarismo o la apologética.

No ha de extrañar por ello que sea posible encontrar interpretaciones de lo más diversas, en ocasiones enfrentadas, por lo que respecta al posible vínculo entre cristianismo y capitalismo. Desde un Amintore Fanfani para el que el cristianismo ${ }^{116}$ representa más bien una cosmovisión antagónica a la del capitalismo hasta interpretaciones que encuentran una conexión de causalidad casi directa entre ambos. Sea como fuere, lo cierto es que, por un lado, el capitalismo existía antes de Lutero y, por otro, los primeros negocios capitalistas (los de las familias Fugger y Médici, por ejemplo) financiaron más bien a la Iglesia de Roma - no en vano hubo hasta tres papas de la dinastía Médici- antes que al protestantismo. De este modo, y en el mejor de los casos, las consecuencias económicas derivadas de la versión del cristianismo inaugurada por Lutero constituirían «una revolución que no ha querido ni previsto, pero que deriva de su dialéctica ${ }^{117}$. De manera análoga, podría decirse que quizás Weber tampoco quiso ni previó las consecuencias de su trabajo, dándose la circunstancia de que tuviese algo de razón en lo que dijo, no así en todo lo que se ha interpretado que dijo (aquello que se ha «derivado de su dialéctica»). Esta descuidada interpretación se manifiesta en primera instancia, tal y como se ha expresado aquí, en la desidia mostrada al eliminar con tanta frecuencia las comillas que Weber pusiera al término «espíritu» en el título de su obra, desvirtuando notablemente y ab initio el mensaje que pretendía transmitir. El espíritu del capitalismo no es el capitalismo en sí. Ni siquiera se trata de sus fundamentos, se trata más bien de la cosmovisión o actitud vital que se aprecia tras él y que se sitúa allende sus fundamentos.

\footnotetext{
116 Fanfani se refiere al cristianismo previo a la Reforma.

117 Hauser 1926. Citado en: Crouzet 2000, 198.
} 
En este sentido, se ha aludido aquí a la importancia de ciertos rasgos del protestantismo sobre la cuestión, tales como una preponderancia de la fe frente a las obras o un ascetismo intramundano en lo religioso que ha devenido en una especial austeridad en lo económico. Otro factor cuya influencia resultaría interesante valorar sería el hecho de que la mayor independencia de los protestantes con respecto a una jerarquía eclesial hubiera podido suponer el desarrollo de un sentimiento de comunidad especialmente robusto y arraigado, algo que podría considerarse clave en el desarrollo de cualquier economía, independientemente del conjunto de creencias y ritos o incluso del propio sistema económico en el que tal sentimiento se enmarque. En este orden de ideas, y por ofrecer algún ejemplo, un aspecto que a menudo es pasado por alto, a pesar de su importancia crucial, es la del grado de intervención que se ha concedido a las jerarquías de una y otra confesión -católica y protestante- tanto sobre la vida privada de sus feligreses como sobre la pública de los diferentes Estados. Mientras suele sugerirse que el protestantismo opta por una intervención discreta y fuera de la estructura del Estado, en los países católicos ha de admitirse que esto no ha ocurrido así. En esta línea, se ha apuntado a que «el protestantismo (...) destruyó la unidad del Estado en la esfera religiosa (...) desde aquel momento y en adelante el Estado adoptó una actitud más proclive con respecto al capitalismo; ya no tenía un credo que defender, sino únicamente intereses» ${ }^{118}$. De este modo, se ha llegado a afirmar ${ }^{119}$ que el vínculo «descubierto» entre protestantismo y capitalismo podría entenderse como un intento de legitimar el capitalismo desde una perspectiva de apariencia neutral como es la de la religión. Una interpretación que, de ser correcta, supondría que lo que Weber habría descubierto no sería una explicación sino una excusa; una coartada, si se quiere.

Más allá de la evidente multiplicidad de interpretaciones que hasta hoy se han construido a partir de la obra de Weber, y de la desvirtuación y abusos que de ella hayan podido derivarse, no sería justo terminar sin insistir en reconocerle al trabajo de Weber el mérito de abordar de un modo verdaderamente novedoso los interesantes vínculos que puedan existir entre la ética religiosa en general y la vida económica o, como diría Weber, «nuestra moderna (...) cultura terrenal ["diesseitig" gerichteten] ${ }^{120}$. Todo ello proponiendo, en muchos aspectos, explicaciones realmente inspiradas. En este sentido, queda fuera de toda duda la importancia de la contribución de Weber a la sociología al abordar la cuestión del posible vínculo entre creencias religiosas y formas económicas. Weber se convirtió con ello en un auténtico pionero en el desarrollo y exposición de formas de sistematización en la investigación dentro de una disciplina relativamente huidiza como la ciencia social, considerada hoy por algunos una ciencia «blanda» ${ }^{121}$. Dicho esto, ha de admitirse la dificultad -sino imposibilidad- de validar de manera científica el contenido de su tesis. Su consideración habría por tanto de limitarse al papel que, como un factor cultural más, un hecho tan omniabarcador como es el religioso ha podido introducir, de manera poco precisa y difícilmente delimitable, en la configuración de nuestra civilización.

\footnotetext{
118 Fanfani 1935, 187-188.

119 García Blanco 1986, 81.

120 Weber 2009, 106.

121 Storer 1967; Hayek 1978; Cole 1983.
} 


\section{Bibliografía}

\subsection{Fuentes}

Obras de san Agustín en edición bilingüe. Tomo VI: Tratados sobre la graciaAristóteles, 1988, Política (trad. Manuela García Valdés), Madrid.

Clemente de Alejandría, 2003, Stromata IV-V (trad. Marcelo Merino Rodríguez), Madrid. John Scotus Eriugena, 2010 [ca. 864], "Periphyseon (On the Division of Nature)", in A. Hyman y J. Walsh (eds.) Philosophy in the Middle Ages. The Christian, Islamic, and the Jewish Traditions, Cambridge.

Luther, M., 1897, "Von der Freiheit eines Christenmeschen" [De la libertad de un cristiano], in Martin Luthers Werke, Kritische Gesammtausgabe (Weimarer Ausgabe). Abteilung 1: Schriften, Bd. 7: Schriften der Jahre 1520-1521 (einschl. Predigten, Disputationen). Weimar.

Luther, M., 1899, "De votis monasticis Martini Lutheri iudicium. 1521" [Juicio de M. Lutero sobre los votos monásticos], in Martin Luthers Werke, Kritische Gesammtausgabe (Weimarer Ausgabe). Abteilung 1: Schriften, Bd. 8: Schriften, Predigten, Disputationen 1520/21. Weimar.

Luther, M., 1905, "Sermon von dem unrechten Mammon" [Sermón del injusto Mammon, para el domingo siguiente a la Ascensión, del 17 de agosto de 1522], in Martin Luthers Werke, Kritische Gesamtausgabe (Weimarer Ausgabe). Abteilung 1: Schriften, Bd. 10 III: Predigten 1522, Weimar.

Luther, M., 1908, "De servo arbitrio", in Martin Luthers Werke, Kritische Gesammtausgabe (Weimarer Ausgabe). Abteilung 1: Schriften, Bd. 18: Schriften 1525, Weimar.

Luther, M., 1914, "An die Pfarrherrn, Wider den Wucher zu predigen" [Exhortación a los párrocos para que prediquen contra la usura], in Martin Luthers Werke, Kritische Gesamtausgabe (Weimarer Ausgabe). Abteilung 1: Schriften, Bd. 51: Predigten 1545/46; Auslegung des 23. und 101. Psalms 1534/36; Schriften 1540/41; Sprichwörter-Sammlung, Weimar.

Luther, M., 1931, "Luther an Melanchthon" [Carta a Melanchthon del 1 de agosto de 1521], in Martin Luthers Werke, Kritische Gesamtausgabe (Weimarer Ausgabe). Abteilung 4: Briefwechsel, Bd. 2: Briefe 1520-1522, Weimar.

Luther, M., 2000 [1529], "Catecismo mayor", in Libro de Concordia. Las Confesiones de la Iglesia Evangélica Luterana (ed. Andrés A. Meléndez). Saint Louis.

Luther, M., 2009 [1524], Sobre el comercio y la usura (trad. Esteve Serra), Palma de Mallorca.

Machiavelli, N., 1883, Discourses on the First Decade of Titus Livius, London.

Maestro Eckhart, 2011a [ca. 1320], "Sermón El templo vacío", in Maestro Eckhart El fruto de la nada y otros escritos (trad. Amador Vega Esquerra), Madrid.

Maestro Eckhart, 2011b [ca. 1320], "Del ser separado", in Maestro Eckhart El fruto de la nada y otros escritos (trad. Amador Vega Esquerra), Madrid.

Maestro Eckhart, 2011c [ca. 1320], "Proverbios y leyendas", in Maestro Eckhart El fruto de la nada y otros escritos (trad. Amador Vega Esquerra), Madrid.

Nicolás de Cusa, 1957 [1440], De Docta Ignorantia, Buenos Aires.

Pseudo Dionisio Areopagita, 2007 [ca. 530], “Carta al monje Gayo”, in T. H. Martín-Lunas (ed.), Obras Completas, Madrid.

Suetonio Tranquilo, C., 1999, Vida de los doce césares, vol. IV (trad. M. Bassols de Climent), Madrid. 
Weber, M., 1986, Gesammelte Aufsätze zur Religionssoziologie. Band 1, Tübingen.

Weber, M., 2009 [1905], La ética protestante y el «espíritu» del capitalismo (trad. J. Abellán García), Madrid.

\subsection{Elenco bibliográfico}

Abellán, J., 2009 [1905], “Estudio preliminar”, in M. Weber, La ética protestante y el «espíritu» del capitalismo, Madrid.

Attali, J., 2011, Los judios, el mundo y el dinero. Historia económica del pueblo judio (trad. V. Goldstein), Buenos Aires.

Baxter, R., 1673, "A Christian Directory or A Sum of Practical Theology, and Cases of Conscience" in The Practical Works of Richard Baxter, vol. I, London.

Besnard, Ph., 1970, Protestantisme et capitalisme. La controverse postwébérienne, Paris.

Bloch, E., 1921, Thomas Müntzer, teólogo de la revolución (trad. J. Deike Robles), Madrid.

Boltanski, L. y Chiapello, E., 2011 [1999], Le nouvel esprit du capitalisme. Paris.

Calderón de la Barca, P., 1987, La vida es sueño (ed. E. Rodríguez Cuadros), Madrid.

Cantoni, D., 2015, "The Economic Effects of the Protestant Reformation: Testing the Weber Hypothesis in the German Lands", Journal of the European Economic Association 13, 561-598.

Carlyle, T., 1985 [1841], Los héroes (trad. Pedro Umbert), Madrid.

Cole, S., 1983, “The Hierarchy of the Sciences?”, American Journal of Sociology 89, 111-139.

Crouzet, D., 2000, Calvino (trad. Ignacio Hierro), Barcelona.

Disselkamp, A., 1994, L'éthique protestante de Max Weber. Paris.

Fanfani, A., 1935, Catholicism, Protestantism and Capitalism. London.

Forcese, D. P., 1968, "Calvinism, Capitalism and Confusion: The Weberian Thesis Revisited", Sociological Analysis 29, 193-201.

García Blanco, J. M., 1986, "Industrialización, capitalismo y racionalidad en Max Weber", Reis: Revista Española de Investigaciones Sociológicas 35, 81-87.

Gil Villegas, F., 2003, "Introducción del editor", in M. Weber, La ética protestante y el espíritu del capitalismo, México.

Gil Villegas, F., 2005, "Cien años de debate en torno a la tesis weberiana sobre la ética protestante", Sociológica 59, 137-169.

Gilbert, M., 2011, “Où en sont les études sur le Siracide?”, Biblica 92, 161-181. Roma.

Goethe, J. W., 1809, Die Wahlverwandtschaften, 2 Bde. Tübingen.

Guiso, L., Sapienza, P., y Zingales, L., 2003, "People's opium? Religion and economic attitudes", Journal of Monetary Economics 50, 225-282.

Hauser, H., 1926, “À propos des idées économiques de Calvin”, in H. Linden, F. L. van der Ganshof y G. G. Dept (eds.) Mélanges d'Histoire Offerts á Henri Pirenne par ses Anciens Élèves et ses Amis a l'Occasion de sa Quarantième Année d'Enseignement a l'Université de Gand, Bruxelles.

Hayek von, F. A., 1978, "La Pretensión del Conocimiento", conferencia en homenaje de Alfred Nobel, pronunciada el 11 de diciembre de 1974, in Los Premios Nobel de Economía 1969-1977, México.

Horkheimer, M., 2010 [1947], Crítica de la razón instrumental (trad. Jacobo Muñoz Veiga), Madrid.

Kierkegaard, S., 2009 [1843], Temor y temblor (trad. Vicente Simón Merchán), Madrid.

Kierkegaard, S., 2009 [1850], Ejercitación en el cristianismo (trad. D. Gutiérrez Rivero), Madrid. 
Küng, H., 1978, ¿Existe Dios? Respuesta al problema de Dios en nuestro tiempo (trad. José María Bravo Navalpotro), Madrid.

MacCulloch, D., 2003, Reformation. Europe's House Divided: 1490-1700, London.

MacKinnon, M. H., 1993, "The Longevity of the Thesis: A Critique of the Critics", in H. Lehmann y G. Roth (eds.) Weber's Protestant Ethic: Origins, Evidence, Contexts. Cambridge.

Maestro Cano, I. C., 2016, "La visión protestante del derecho", Revista Española de Derecho Constitucional 108, 157-179.

Marx, K., 1844, "Zur Kritik der Hegelschen Rechtsphilosophie", in Karl Marx-Friedrich Engels Werke. Bd. I, Berlin.

Marx, K., 2007, Elementos fundamentales para la crítica de la economía política (Grundrisse) 1857-1858. Vol. 3 (eds. José Aricó, Miguel Murmis y Pedro Scarón), México.

Meehl, P. E., 1997, “The problem is epistemology, not statistics: Replace significance tests by confidence intervals and quantify accuracy of risky numerical predictions", in L. L. Harlow, S. A. Mulaik y J. H. Steiger (eds.) What if there were no significance tests?, Mahwah.

Nietzsche, F., 1983, Asi hablaba Zaratustra (trad. Carlos Vergara), Madrid.

Offenbacher, M., 1901, Konfession und Soziale Schichtung: Eine Studie über die wirtschaftliche Lage der Katholiken und Protestanten in Baden, Tübingen.

Papini, G., 1962, Historia de Cristo (trad. Agustín Piaggio), México.

Parsons, T., 1948, “Max Weber's Analysis of Capitalism and Modern Institutions”, in H. E. Barnes (ed.) An Introduction to the History of Sociology, Chicago.

Proudhon, P. J., 1983 [1840], ¿Qué es la propiedad? (trad. Rafael García Ormaechea), Barcelona.

Rifkin, J., 1995, The End of Work. The Decline of the Global Labor Force and the Dawn of the Post-Market Era, New York.

Rodríguez, J. (ed.). (2005). En el centenario de La ética protestante y el espiritu del capitalismo. Madrid.

Rüger, H. P., 1984, "Le Siracide: un livre à la frontière du canon", in J. D. Kaestli y O. Wermelinger (eds.) Le Canon de l'Ancien Testament. Sa formation et son histoire, Genève.

Rupp, H. F., 1996, "Philipp Melanchthon (1497-1560)", Prospects: the Quarterly Review of Comparative Education 26, 611-621.

Schaltegger, C. A. y Torgler, B., 2009, "Was Weber Wrong? A Human Capital Theory of Protestant Economic History: A Comment on Becker and Woessmann", CREMA Working Paper Series, Center for Research in Economics, Management and the Arts, http://www. crema-research.ch/papers/2009-06.pdf [acceso: 04.07.2018].

Sombart, W., 1911, Die Juden und das Wirtschaftsleben, Leipzig.

Sproul, R. C., 1997, Willing to Believe: The Controversy over Free Will, Grand Rapids.

Steck, W., 1991, "Protestantische Attribute: Individualität-Modernität-Liberalität. Eine Meditation", in R. Ziegert (ed.) Protestantismus als Kultur, Bielefeld.

Stirner, M., 1844, El único y su propiedad, Madrid.

Storer, N. W., 1967, "The Hard Sciences and the Soft: Some Sociological Observations", Bulletin of the Medical Library Association 55, 75-84.

Tawney, R. H., 1926, Religion and the Rise of Capitalism, New Brunswick.

Tocqueville, A., 1840, Democracy in America. Vol. 2 The social influence of democracy, New York.

Venn, J., 1866, The Logic of Chance: An Essay on the Foundations and Province of the Theory of Probability, with Especial Reference to Its Application to Moral and Social Science, London/Cambridge. 
Wesley, J., 1786, “Thoughts upon Methodism”, in The Complete Works of John Wesley, Vol. 13: Letters, writings, Albany.

\subsection{Referencias hemerográficas}

Agencias ANSA y EFE, "Papa Francisco: 'El dinero es el estiércol del diablo"”. La Nación, Buenos Aires, 28 de febrero de 2015, http://www.lanacion.com.ar/1772302-papa [acceso: 04.07.2018].

Bedoya, J. G., “'Cerditos' en la UE: ¿Son los países católicos manirrotos?”, El País, Madrid, 8 de enero de 2012, http://sociedad.elpais.com/sociedad/2012/01/07/actualidad/ 1325970360_782608.html [acceso: 04.07.2018].

Florida, R., "How Heavy Metal Tracks the Wealth of Nations", The Atlantic Citylab, Washington, 26 de mayo de 2014. http://www.citylab.com/politics/2014/05/how-heavy-metaltracks-the-wealth-of-nations/371473/ [acceso: 04.07.2018].

Sánchez-Vallejo, M. A., "La economía entiende muy poco de dioses", El País, Madrid, 23 de agosto de 2010, http://elpais.com/diario/2010/08/23/sociedad/1282514401_850 215.html [acceso: 04.07.2018].

Torreblanca, J. I., "Prejuicios", El País, Madrid, 5 de abril de 2010, http://elpais.com/ diario/2010/04/05/internacional/1270418409_850215.html [acceso: 04.07.2018]. 
